THEMATIC PAPER

\title{
Improving access to mental healthcare for displaced Syrians: case studies from Syria, Iraq and Turkey
}

\author{
P. Hughes, ${ }^{1}$ Z. Hijazi ${ }^{2}$ and K. Saeed ${ }^{3}$
}

${ }^{1}$ Consultant Psychiatrist, Springfield University Hospital, London, UK, email peter. -tr.nhs.uk ${ }^{2}$ Mental Health, Psychosocial and Protection Specialist, email zeinab.y.hijazi@gmail.com

${ }^{3}$ Regional Advisor, EMRO Eastern Mediterranean Region, WHO, email saeedk@emro.who.int

Acknowledgements to $\mathrm{WHO}$ EMRO, EURO and UNHCR.
The conflict in Syria has led to an unprecedented humanitarian crisis that extends across multiple countries in the area. Mental health services were undeveloped before and now face huge strain and unmet need. The World Health Organization and others have developed a programme to build capacity in the delivery of mental health services in an integrated healthcare package to refugees and displaced people. The tool used for this is the mhGAP Intervention Guide and complementary materials. In this paper we refer to training in Turkey, Iraq and Syria where health professionals were trained to roll out this community-based integrated approach through primary healthcare. We describe field case examples that show the complexity of situations that face refugees, displaced people and those caught in active conflict. Training improved the knowledge and skills for managing mental health disorders in primary healthcare. Further work needs to be done to demonstrate greater access to and utilisation of services, client outcomes and organisational change with this approach.

The Eastern Mediterranean region carries the world's largest burden of displaced populations (Table 1). By the end of 2015, more than half of all refugees globally had come from just three countries in the region: the Syrian Arab Republic, Afghanistan and Somalia. The situation in these countries is not only adversely affecting their own social, economic and health institutions and systems, but is creating ripple effects extending to all parts of the globe.

The conflict in Syria, which is now in its sixth year, is almost unprecedented in the magnitude of

Table 1

Numbers of refugees and displaced people in the Eastern Mediterranean region

\begin{tabular}{|l|r|l|l|l|l|}
\hline & $\begin{array}{r}\text { No. of } \\
\text { people }\end{array}$ & $\begin{array}{l}\text { No. of } \\
\text { camps }\end{array}$ & $\begin{array}{l}\% \text { in } \\
\text { camps }\end{array}$ & $\begin{array}{l}\% \text { not in } \\
\text { camps }\end{array}$ & $\begin{array}{l}\% \text { aged } \\
\text { under } 18\end{array}$ \\
\hline Total no. of Syrian refugees & 4841807 & & & & \\
\hline No. of internally displaced people in Syria & 6600000 & & & & \\
\hline No. of Syrian refugees in Iraq & 246123 & 9 & $39 \%$ & $61 \%$ & $38 \%$ \\
\hline No. of Syrian refugees in Turkey & 2748862 & 22 & $8 \%$ & $92 \%$ & $55 \%$ \\
\hline
\end{tabular}

Source of data: website of the UN Office for the Coordination of Humanitarian Affairs (OCHA) (http://www.unocha.org), 2016. humanitarian and public health catastrophe. Continued heavy fighting between the Syrian army and various opposition forces, and prolonged increases in sectarian violence in Iraq, have resulted in an estimated 25 million people currently in need of humanitarian assistance in the region.

According to United Nations Office for the Coordination of Humanitarian Affairs (OCHA, 2016), over a quarter of a million Syrians have been killed since March 2011; 4.8 million have sought refuge status outside of Syria and 6.5 million are internally displaced, making Syria the largest displacement crisis globally. Civilians have been disproportionately affected by the conflict.

Emergencies not only cause almost universal distress but also result in increased rates of mental disorders. The World Health Organization (WHO) \& United Nations High Commissioner for Refugees (2015) estimated that, during an emergency, on average $5-10 \%$ of a population may develop mental disorders. According to the WHO World Mental Health Survey Consortium (2004), epidemiological data in conflict-affected populations show a prevalence of $15.4 \%$ for post-traumatic stress disorder (PTSD) and 17.3\% for depression, compared with $7.6 \%$ and $5.3 \%$, respectively, in non-conflict zones. The prevalence of mental disorders is high in the Middle East, due to conflict. The International Medical Corps, an international non-governmental organisation (NGO), reports that the most common mental health condition found in affected populations is severe emotional distress. It also reports rising levels of psychosocial distress (Van Ommeren et al, 2015).

Decreased funding for the response, coupled with weak national mental health systems, has led to overburdened governments and organisations. The coverage of mental health and psychosocial support services (MHPSS) among internally displaced persons (IDPs) and refugees is minimal, while demand for services grows. Effective response includes preparedness and provision of MHPSS in a multi-layered and cross-sectoral response that addresses complex and comprehensive needs of displaced populations. But there are shortages of staff, both specialised and non-specialised, to deliver mental health and psychosocial interventions.

To improve the overall quality, availability and accessibility of mental health services, UN agencies, such as the WHO and Office of the United Nations High Commissioner for Refugees (UNHCR), and 
international non-governmental organisations (INGOs) such as International Medical Corps, with the collaboration of local partners, have been integrating mental healthcare into the general healthcare infrastructure.

In this paper we review a training programme in Iraq, Turkey and Syria that aims to improve access to mental healthcare for affected vulnerable populations. The training programme builds capacity through seed training sessions in roll-out of the mhGAP model in primary care.

\section{Methods}

Training sessions in all three countries were set up as a training of trainers (TOT) and were based on the WHO mhGAP programme and intervention guide, where supervision and teaching skills were developed. In Iraq the humanitarian version (mhGAP-HIG) was used. Training sessions were facilitative and culturally sensitive, run as a partnership of local and international trainers. Selection of mhGAP modules was country specific and needs led, based on the most common mental health disorders seen at the primary care level. Stress disorders, children's developmental and behavioural conditions and somatisation were priorities. Participatory methods of teaching were used in both theoretical and supervision components, and included one-on-one, group, role-play, videos and other participatory training methods, complemented by a WHO training package of resources. The participants (Table 2) included healthcare

\section{Table 2}

Participants in the training programmes

\begin{tabular}{|c|c|c|c|c|}
\hline Country & $\begin{array}{l}\text { No. of } \\
\text { participants }\end{array}$ & $\begin{array}{l}\text { Professional } \\
\text { background }\end{array}$ & $\begin{array}{l}\text { No. of } \\
\text { men }\end{array}$ & $\begin{array}{l}\text { No. of } \\
\text { women }\end{array}$ \\
\hline \multirow{3}{*}{ Syria } & \multirow{3}{*}{30} & Psychiatrists 20 & \multirow{3}{*}{20} & \multirow{3}{*}{10} \\
\hline & & Psychologists 4 & & \\
\hline & & Social workers 6 & & \\
\hline \multirow{2}{*}{ Turkey } & \multirow{2}{*}{16} & Psychiatrists 13 & \multirow{2}{*}{13} & \multirow{2}{*}{3} \\
\hline & & Other doctors 3 & & \\
\hline \multirow{5}{*}{ Iraq } & \multirow{5}{*}{$\begin{array}{l}52(2 \\
\text { training } \\
\text { sessions) }\end{array}$} & Psychiatrists 7 & \multirow{5}{*}{36} & \multirow{5}{*}{16} \\
\hline & & Psychologists 7 & & \\
\hline & & Nurses 7 & & \\
\hline & & $\begin{array}{l}\text { Psychosocial } \\
\text { workers } 6\end{array}$ & & \\
\hline & & $\begin{array}{l}\text { Primary care/other } \\
\text { doctors } 25\end{array}$ & & \\
\hline
\end{tabular}

Table 3

Training results

\begin{tabular}{|c|c|c|}
\hline Country & $\begin{array}{l}\text { Change in score on a test } \\
\text { administered before and } \\
\text { after training }\end{array}$ & Overall feedback \\
\hline \multirow{3}{*}{ Iraq } & \multirow{3}{*}{$+8.5 \%$} & Very good $72 \%$ \\
\hline & & Average $25 \%$ \\
\hline & & Insufficient $3 \%$ \\
\hline Syria & $+20 \%$ & $\begin{array}{l}\text { Mean score 'agree/ } \\
\text { strongly agree' }\end{array}$ \\
\hline Turkey & $+10 \%$ & $\begin{array}{l}\text { Overall mean score } \\
\text { 'good' }\end{array}$ \\
\hline
\end{tabular}

providers from the IDP and refugee communities, leveraging the role of specialists more effectively by refocusing their work from clinical care to training, supervision and management of complex cases.

\section{Results}

The results of the training sessions are briefly summarised in Table 3. Below, we describe field case examples that show the complexity of situations that face refugees, displaced people and those caught in active conflict.

\section{Syria, February 2014}

Syria field case examples

Case 1. A single male in his 50s witnessed an explosion in front of his house several months ago. His mother was wounded. He cannot go out of his house alone. He is hesitant, sleeps with earplugs, and is in hiding because he fears another explosion. He uses alcohol to lessen his anxiety.

Case 2. A 32-year-old single male IDP merchant has chronic stress because of bombardment. His symptoms include headache, dyspnoea, racing heart, insomnia and sensitivity to noise.

\section{Training sessions}

The mhGAP TOT in Syria was held in a secure part of Damascus, at a time when conflict was ongoing. Programmatically, it was successful, with roll-out in many areas and a momentum that was astonishing in light of the unstable security situation. Participants reported the challenges of attending the training due to conflict even in the city, and trainers shared similar concerns regarding on-the-job training and supervision. Participants prioritised stress conditions, including loss and violence, and were asked to provide case examples from the field as part of ongoing supportive supervision and training through case discussions.

Despite the challenges, the mhGAP programme is achieving great success in Syria in terms of an increasing number of doctors providing mental health through primary care. This success has been observed by local and expatriate trainers involved in the roll-out of mhGAP in the country.

\section{Iraq, 2015}

\section{Iraq field case examples}

Case 1. An 11-year-old child with sleeping problems experiences fear, crying, depressive symptoms, bedwetting and poor concentration. He saw dead people during displacement from Syria. His own life was threatened many times and he was exposed to abuse and family neglect. He suffers from PTSD.

Personal story of participant. 'We ran away from ISIS and lost everything. It is hard to adjust. Recently I planned to kill myself with all the abuse I face now.' 


\section{Training sessions}

This was TOT using, and piloting, the humanitarian version of the mhGAP, in two centres in northern Iraq, Dohuk and Erbil, the regional capital of Iraqi Kurdistan. Dohuk is close to many refugee and IDP camps, including the Yazidi camps. Participants included psychosocial workers from the refugee and Yazidi community.

The training targeted a varied cadre of health workers serving the local camps, both Yazidi and Syrians displaced by ISIS. Acute stress, bedwetting, grief, PTSD and depression were common. Misuse of tramadol, diazepam and methamphetamine was reported to be a problem. Alcohol use was unusual but was seen, as was suicide.

\section{Turkey, 2016}

Turkey field case examples

Case 1. A 48-year-old single woman, and refugee from Syria for 1.5 years, has stomach pain, back pain, dyspnoea and exhaustion. She takes many medicines and has undergone many physical tests.

Case 2. An 8-year-old child was orphaned at age 3 and was a refugee at age 5 . With a poor social network, he presents as violent, arrogant, with fluctuations of mood, selfishness and lying.

\section{Training sessions}

This training programme arose out of an assessment of need in southern Turkey and northern Syria. There were 12 psychiatrists in the region, and a strong need to build capacity of both doctors and nurses in the management of mental health disorders. Unfortunately, this initial stage focused on doctors only. The target in northern Syria was to provide mental health services and coverage in 60 primary care centres.

Refresher training sessions and follow-up supervision were planned as part of the programme. In southern Turkey the plan was to train 500 doctors, including 150 registered Syrian doctors. Many had experienced adverse life events during displacement to Turkey. Cases cited by participants indicated problems of stress, somatisation and children's problems. Dependency on substances like tramadol was common; substances such as benzodiazepines can be bought easily in northern Syria and are used to self-medicate stress.

Main causes of stress identified by the group were shelling, polygamy, financial difficulties, gender-based violence, loss and political issues. The main problem overall was distress, sometimes severe, caused by displacement, both in Turkey and in northern Syria. Stress reactions reported included crying, isolation, sadness, denial, impaired functioning, vivid memories, getting closer to God, sense of hearing voices, somatisation, anger and numbness.

Suicide was not common but was identified, among men mostly, but also young girls, with cases of hanging, overdose and self-immolation. Children were badly affected by displacement and presented with regression, bedwetting and problem behaviours.

\section{Conclusions}

Both health workers and the general population are under enormous stress due to the conflict. Overwhelmingly, there is the theme of stress, and often severe distress, from displacement and war. Life is on hold and the stress is barely contained. Stress conditions are common, but so are a range of other mental health problems, including somatisation, tramadol use, psychosis and bedwetting. Polypharmacy and gender-based violence are frequent and largely unaddressed.

Refugee workers are an invaluable resource for healthcare delivery. Trainers were struck by the dedication and tireless efforts of the trained health workers. They were personally affected by the conflict and yet the level of altruistic, humanitarian drive was high. As such, an important strand of training was on self-care.

The uncertainty and the chronic stress have paradoxically led to an environment where mental health can be incorporated into general healthcare, provided by highly motivated workers. Even in active conflict areas, trainers reported impressive progress in rolling out mental health into primary care.

Key to moving these programmes further is ongoing resources, including financial, supervisory and professional development. Additional efforts, resources and funds need to be invested in a rigorous evaluation of patient-level impact as part of the roll-out of integrating mental healthcare and primary care.

\section{References}

OCHA (2016) Overview of Global Humanitarian Response. Available at https://docs.unocha.org/sites/dms/CAP/Overview_of_Global_ Humanitarian_Response_2014.pdf

Van Ommeren, M., Hanna, F., Weissbecker, I., et al (2015) Mental health and psychosocial support in humanitarian emergencies. Eastern Mediterranean Health Journal, 21, 498-502.

WHO World Mental Health Survey Consortium (2004) Prevalence, severity, and unmet need for treatment of mental disorders in the World Health Organization surveys. JAMA, 291, 2581-2590.

World Health Organization \& United Nations High Commissione for Refugees (2015) Global Burden of Disease. WHO.

International Congress of the Royal College of Psychiatrists 2017

Edinburgh, 26-29 June 2017

Psychiatry Without Borders

After a hugely successful congress in London this year the College is already planning the 2017 Congress in Edinburgh. A call for poster submissions is due in November 2016.

For further information regarding the Internationa Congress, please email congress@rcpsych.ac.uk 